\title{
Middle Jugular Lymph Node Group (Level
}

III)

National Cancer Institute

\section{Source}

National Cancer Institute. Middle Jugular Lymph Node Group (Level III). NCI Thesaurus.

Code C132511.

Lymph nodes located around the middle third of the internal jugular vein, extending from the inferior border of the hyoid bone (above) to the inferior border of the cricoid cartilage (below). The anterior (medial) boundary is the lateral border of the sternohyoid muscle, and the posterior (lateral) boundary is the posterior border of the sternocleidomastoid muscle. These nodes are at greatest risk for harboring metastases from cancers arising from the oral cavity, nasopharynx, oropharynx, hypopharynx, and larynx. (AJCC 8th ed.) 